\title{
Response to Michael K. Briand
}

\author{
Nelson W. Polsby, University of California, Berkeley
}

$M$ ore or less repeating a piece of my talk at the University of Chicago last year, there are a couple of points I wish to make about the Kettering report.

1. Some sort of peer review should have preceded the Foundation's massive effort at publicizing the findings of its focus group studies. This peer review might have pointed out that there are standards that apply to the conduct of focus groups and could have found out whether in this case these standards were met. After reading $\mathrm{Mr}$. Briand's communication, we still do not know. Until we find out, replication by others will be difficult.

2. The Foundation has it within its resources to convert hypotheses generated by its focus groups into better, more carefully qualified findings, e.g., through the use of survey research, and should have done so.

3. There are good reasons-one or two of which I gave-to wonder if the findings as presented could bear the inferential burden the Foundation and its president were putting on them.

4. These observations merely invoke standards of inquiry familiar in the social sciences. My purpose in making them was to affirm the existence of these standards, and their relevance to contemporary social discourse.

Of course some of the comments
Briand makes I agree with. But I think I will pass on the questions he raises about my "honesty" and other "motives." I wonder at his readiness to patronize "experts"' (whoever they might be), his groundless imputations that merely questioning the Kettering study constitutes an inappropriate claim about "truth" or an attempt to silence our fellow citizens, his gratuitous side-swipe at Sidney Verba, who makes his research designs and his questions available for collegial scrutiny, as Kettering does not, and so on. These passages in Briand's letter do not seem to me to show off "democratic dialogue" to good advantage, if that was his intention.

\section{An Assessment of Articles About Women in the "Top 15" Political Science Journals"}

\author{
Rita Mae Kelly, Arizona State University \\ Kimberly Fisher, Arizona State University
}

\begin{abstract}
As the media and the voting public grow increasingly interested in politically active women, political scientists of all subdisciplines are well advised to take stock of the knowledge their discipline has accumulated about "women and politics." Though numerous social science journal articles discuss women's political activities, relatively few of these articles have been published in the leading political science journals. The American Political Science Review, for example, published a mere 24 articles related to women from its debut in 1906 through the fourth issue of 1991 .

Here we explore the range, scope, and content of the articles dealing with women and women's issues published in the 15 political science journals receiving the highest impact
\end{abstract}

ratings from members of the field. ${ }^{1}$ This assessment addresses the following questions:

(1) What, if any, patterns exist within and between journals, and across decades?

(2) What topics and perspectives are discussed?

(3) What expertise would a person gain about women by reading only these journals?

\section{Methodology}

The journals included in this study were identified by a 1990 Political Studies Association survey of journals as having the strongest impact on the discpline. For each journal, we examined all issues from the first publication through the final 1991 issue, identifying, annotating, and assessing each article in light of the above questions. (The journals and articles are listed in the appendix.) To be as inclusive as possible, we examined all articles containing the following words in their titles, subtitles, abstracts, or first paragraphs: women, female, feminism, lesbian, Equal Rights Amendment, or abortion; and those discussing a female theorist (such as Hannah Arendt) or political leader (such as Indira Gandhi). Articles whose titles, subtitles, abstracts, or first paragraphs contained these words-affirmative action, civil rights, equal rights, equality, sex, sexuality, pornography, gender, homosexuality, fertility, family planning, child care, or family -were scanned first for relevancy to women. Our search identified a total 